\title{
Activation of Wnt/ $\beta$-catenin signaling in ESC promotes rostral forebrain differentiation in vitro
}

\author{
Nozomu Takata $^{1} \cdot$ Eriko Sakakura $^{1} \cdot$ Yoshiki Sasai $^{2}$
}

Received: 15 October 2015 / Accepted: 27 October 2015 / Published online: 12 November 2015 / Editor: Tetsuji Okamoto

(C) The Author(s) 2015. This article is published with open access at Springerlink.com

\begin{abstract}
Wnt} / \beta$-catenin signaling is crucial for maintenance of pluripotent state of embryonic stem cell (ESC). However, it is unclear how $\mathrm{Wnt} / \beta$-catenin signaling affects the differentiation ability of ESC, especially with regard to rostral forebrain cells. Here, using Rax, rostral forebrain marker, and Wnt/ $\beta$ catenin reporter lines, we report ratio of $\mathrm{Rax}^{+}$and Wnt responding tissue $\left(\mathrm{Wnt}^{+}\right)$patterns, which were affected by seeding number of ESC in three-dimensional culture system. Surprisingly, we found $\beta$-catenin level and localization are heterogeneous in ESC colony by immunostaining and timelaps imaging of $\beta$-catenin-mEGFP signals. Moreover, activation of Wnt signaling in ESC promoted expression level and nuclear localization of $\beta$-catenin, and mRNA levels of Wnt antagonists, axin 2 and $d k k 1$, leading to upregulating $\mathrm{Wnt} / \beta$ catenin reporter in ESC state and Rax expression at differentiation culture day 7. Together, our results suggest that activation of Wnt signaling in ESC promotes the differentiation efficacy of rostral forebrain cells. Wnt-priming culture method may provide a useful tool for applications in the areas of basic science and molecular therapeutics for regenerative medicine.
\end{abstract}

Dr. Yoshiki Sasai should be corresponding author, if he was alive.

Electronic supplementary material The online version of this article (doi:10.1007/s11626-015-9975-y) contains supplementary material, which is available to authorized users.

Nozomu Takata

nozomutakata@cdb.riken.jp; nozomutakata@gmail.com

1 Laboratory for in vitro Histogenesis, RIKEN Center for Developmental Biology, 2-2-3 Minatojima-minamimachi, Chuou-ku, Kobe, Hyogo 650-0047, Japan

2 Laboratory for Organogenesis and Neurogenesis, RIKEN Center for Developmental Biology, 2-2-3 Minatojima-minamimachi, Chuou-ku, Kobe, Hyogo 650-0047, Japan
Keywords Wnt/ $\beta$-catenin signaling $\cdot$ Wnt antagonist $\cdot$ Rostral forebrain $\cdot$ Rax $\cdot$ Embryonic stem cells $\cdot$ Regenerative medicine

\section{Introduction}

Forebrain is derived from neural plate, called neural ectoderm (Ruiz i Altaba 1998), which is subdivided into telencephalon and diencephalon (Markakis 2002). Diencephalon contains the hypothalamus and eyes in vertebrate (Sinn and Wittbrodt 2013). These developmental events involving forebrain patterning are largely conserved among species (Wilson and Houart 2004).

In rostral forebrain cells, Rax, transcriptional factor is expressed during early development (Furukawa et al. 1997; Ohuchi et al. 1999). In fact, disruption of Rax gene led to severe defects involving forebrain and eye development (Mathers and Jamrich 2000; Zhang et al. 2000; Andreazzoli et al. 2003; Nakagawa 2004). Additionally, misexpression of Rax gene led to duplication of rostral neural tube and eye (Mathers et al. 1997). Moreover, genetic mutations of the human RAX were found in a patient with anophthalmia and microphthalmia, which were ocular birth defects and a cause of congenital blindness (Voronina et al. 2004; Abouzeid et al. 2012). Thus, Rax gene plays crucial roles in forebrain and eye development.

Although its roles are well know as described above, Rax gene has another role as a specific marker for forebrain development. In this regard, for regenerative medicine, monitoring of Rax gene expression is a powerful tool for estimation of forebrain differentiation in vitro.

Previously, using embryonic stem cell (ESC) culture system, Wataya et al. showed efficient induction of hypothalamic tissues expressing Rax gene (Wataya et al. 2008), and Eiraku et al. showed optic cup morphogenesis by monitoring Rax 
expression in live condition (Eiraku et al. 2011). These reports demonstrated clearly that the use of Rax gene monitoring facilitated the analysis of forebrain development, suggesting that innovation of generation and manipulation of such tissues make it possible for regenerative tools to become closer to reality. However, in both methods, Rax expression patterns slightly vary among tissues in vitro (high and low expressions among tissues). Lacking of efficient and stable culture methods may hamper the reliability of future regenerative approaches.

In another aspect of ESC culture system, ESC state is maintained by Wnt signaling activity (Nusse 2008; Nusse et al. 2008; ten Berge et al. 2011). Namely, activation of the Wnt signaling maintains ESCs in a pluripotent state. In addition, ESCs that harbor Wnt activating mutations in the negative regulator APC or in positive regulator $\beta$-catenin indeed have a profound reduction in their ability to differentiate, even following LIF (a ESC maintenance factor) withdrawal (Kielman et al. 2002). Wnt signaling also regulates the lineage differentiation potential of ESCs (Atlasi et al. 2013; Price et al. 2013). 2i conditioned medium (ESC medium containing Wnt agonist, CHIR99021 (CHIR) and Fgf antagonist, PD0325901 (Ying et al. 2008; Li and Ding 2010; Plusa and Hadjantonakis 2014)) improves ESC differentiation rate of neuronal lineages, expressing pan-neural marker, soxl (Marks et al. 2012). Therefore, Wnt signaling in ESC maintenance is important for a potential lineage commitment. However, it is unclear how Wnt activation in ESC state affects rostral forebrain differentiation in vitro.

Here, we observed Rax gene expression with Wnt/ $\beta$-catenin signaling to explore the efficient method, which potentially promotes rostral forebrain differentiation from mouse ESCs.

\section{Materials and Methods}

ESCs maintenance, differentiation, and Wnt-priming method. Mouse ESCs; E14Tg2a (Hooper et al. 1987), Rax::GFP (Wataya et al. 2008), and Rax::GFP//TOP::DsRed (Andrabi et al. 2015) murine ESCs were maintained, and SFEBq culture were performed as described thoroughly by Wataya et al. (2008). Briefly, SFEBq (serum-free floating culture of embryoid body-like aggregates with quick reaggregation) culture is a method that starts with quick reaggregation of dissociated mouse ESCs in each well of a low cell-adhesive coating 96well plate (Nunclon Sphera 96U Bottom Plate 174925; Thermo Scientific, Waltham, MA). For differentiation medium, we used gfCDM (a modified growth factor free chemically defined medium (Wiles and Johansson 1999; Bouhon et al. 2005)), which is free of knockout serum replacement and other growth factors including insulin. Composition of gfCDM was as follows: Iscove's modified Dulbecco's medium (Gibco, Carlsbad, CA) and Ham's F-12 Nutrient mixture (Gibco) are mixed in a one-to-one, supplemented with $1 \mathrm{x}$ chemically defined lipid concentrate (Gibco), monothioglycerol $(450 \mu \mathrm{M})$, purified BSA $(5 \mathrm{mg} / \mathrm{ml})$, and human apo-transferrin $(15 \mu \mathrm{g} / \mathrm{ml})$. In Wnt-priming method, we maintained ESCs with $10 \mu \mathrm{M}$ CHIR99021 (Stemgent, Cambridge, MA) for 2 or $3 \mathrm{~d}$ and then performed SFEBq differentiation in gfCDM. This method has one advantage, because it is not necessary to add additional chemical reagents during forebrain differentiation, meaning not necessary to remove chemical reagents completely (when collecting forebrain tissues for regenerative medicine). Differentiation status was quickly checked by BZ-9000 microscope (KEYENCE, Osaka, Japan), which allows us to monitor fluorescent and transillumination images.

FACS analysis. Fluorescence-activated cell sorting (FACS) analysis was performed as previously described (Kamiya et al. 2011). For cell preparation, cells were dissociated to single cells by TrypLE ${ }^{\text {TM }}$ Express (Gibco, 12605-010) treatment and filtration through Cell Strainer (BD Biosciences, East Rutherford, NJ). Cells in tube were kept on ice until analysis. For population analysis, FACSDiva (BD Biosciences) was used. For data analysis, data were analyzed with FlowJo software. All processes were performed, based on manufacturer's instruction.

Immunohistochemistry, confocal microscope, and image analysis. Immunostaining and cryosectioning were performed as previously described (Wataya et al. 2008; Ohgushi et al. 2015). Briefly, for ESC staining, the ESCs were seeded onto a gelatin-coated 8-well chamber slide (Biocoat Collagen TypeI Cellware 8well Culture Slide 354630; CORNING, Corning, $\mathrm{NY}$ ), and fixed with $4 \%$ paraformaldehyde (PFA) at room temperature for $30 \mathrm{~min}$ and then permeabilized with $0.3 \%$ Triton-X100/PBS solution. After incubation of ESCs in $2 \%$ skim milk/PBS blocking solution, we used specific antibodies in blocking solution as follows: $\beta$-catenin (mouse, 1:500, BD transduction 610153: rabbit, 1:500, C-2206; Sigma-aldrich): GFP (rat, 1/500, 04404-84; Nacalai, San Diego, CA): Nanog (rabbit, 1/1000, RCAB0001P; ReproCell, Yokohama, Japan): Oct3/4 (mouse, $1 / 200$, BD 611202). After washing primary antibodies in $0.05 \%$ Tween/PBS, the staining was visualized using appropriate secondary antibodies conjugated with the fluorescent probes, Alexa Fluor-488 (1:1000, Molecular Probes, Eugene, OR) or Cy3/Cy5 (1:200, Jackson ImmunoResearch, West Grove, PA). We used DAPI (\#11034-56, Nacalai) for counter staining. F-actin was visualized with AlexaFluor-conjugated phalloidin (546 and 647, 1/500, A22283 and A22287, respectively; Invitrogen, Carlsbad, CA). For cryosectioned sample staining, day-7 tissues were fixed with $4 \%$ PFA at room temperature for $30 \mathrm{~min}$ and washed in PBS. Then fixed tissues were in $15 \%$ sucrose/ PBS at $4^{\circ} \mathrm{C}$ for overnight for cryoprotection, followed by cryosection. Immunostaining of cryosectioned sample slides is basically the same as above. Imaging analysis was 
Figure 1. Rostral forebrain marker, Rax::GFP and Wnt reporter, 7Tcf::Cherry expressed in SFEBq-derived tissues. (a) Schematic diagram of SFEBq method. (b) Merged images of transillumination (Trans), Rax::GFP and 7Tcf::Cherry signals in day-7 tissues. Scale bars $100 \mu \mathrm{m}$.

(a)

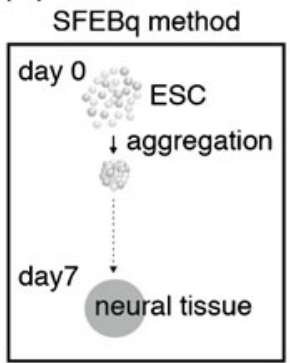

(b)

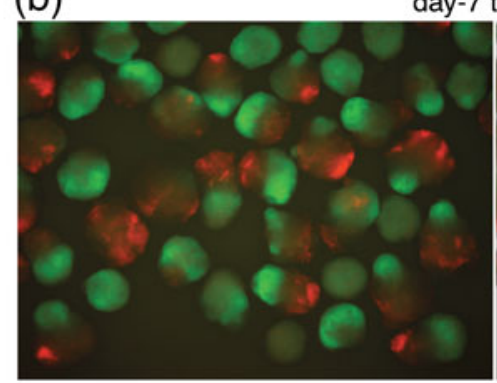

Rax::GFP 7Tcf::Cherry day-7 tissues

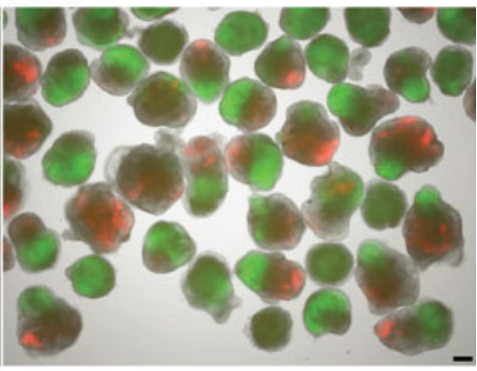

Trans Rax::GFP 7Tcf::Cherry performed using LSM 710 or 780 confocal laser-scanning microscope (Zeiss, Oberkochen, Germany). The Z-scanning images in video 1 were reconstituted from the serial slices of confocal images using imageJ software.

Rosa26 locus targeting vector construction, introduction, and genotyping of $\beta$-catenin-mEGFP knock-in ESCs. For Rosa26 locus knock-in, we obtained Rosa $26 \mathrm{mT} / \mathrm{mG}$ (Muzumdar et al. 2007), a gift from Liqun Luo (plasmid \# 17787; Addgene,
Cambridge, MA) and performed chimeric-PCR to amplify $\beta$ catenin-mEGFP-SV40pA from mouse ESC cDNA and pDONR221-mEGFP (monomeric EGFP). Subsequently, by restriction enzymes, we subcloned $\beta$-catenin-mEGFP-SV40pA PCR products into downstream of pCAG (consisting of the cytomegalovirus enhancer fused to the chicken beta-actin promoter) in Rosa26 $\mathrm{mT} / \mathrm{mG}$ as a backbone vector, which has $5^{\prime}$ (1.1 kbp) and 3' (4.3 kbp) homology arms with pPGK::neo ${ }^{\mathrm{r}}-$ $\mathrm{bGHpA}$ (mT/mG cDNA was removed at this time). Then, we
Figure 2. Seeding number in SFEBq affected the expression patterns of Rax::GFP and

7Tcf::Cherry signals. (a) Schematic diagram of day-7 tissue patterns. (b) Quantification of ratio of day-7 tissue patterns in several seeding number condition. Error bars indicate standard error of the mean of each experiment ( $N=96$ tissues). (c) FACS analysis of day-7 Rax::GFP positive cells in several seeding number condition. (d) Quantification of Rax::GFP expression of day-7 cells. Error bars indicate standard error of the mean of 16 tissues of each experiment.

(a) day-7 tissue patterns

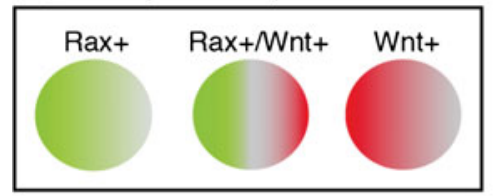

(b)

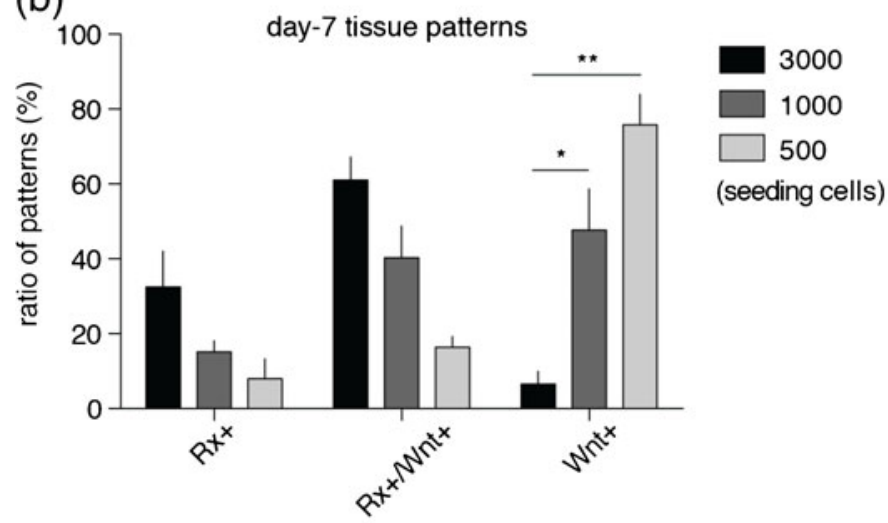

(c)

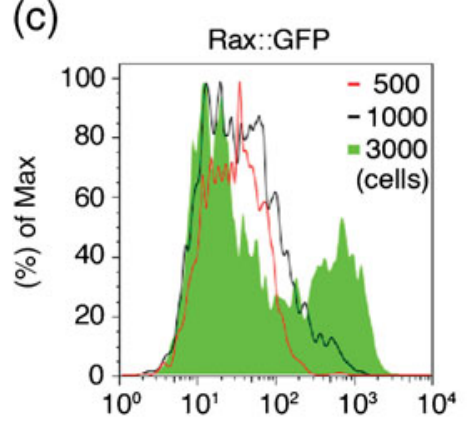

(d)

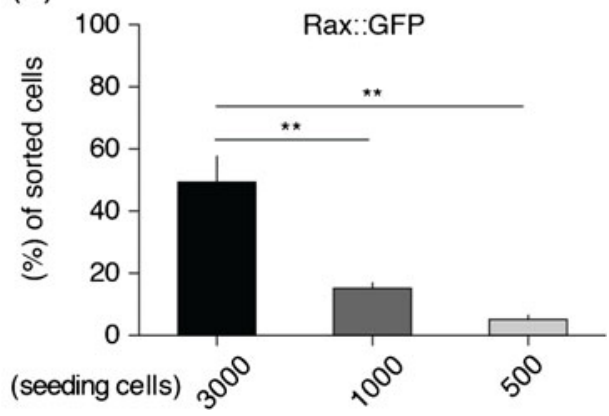


(a)

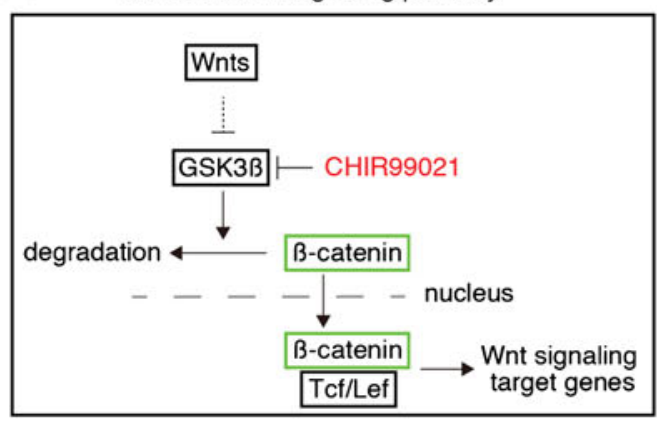

(c)

Rosa26 locus

Targeting vector $\stackrel{1.1 \mathrm{~kb}}{\longrightarrow}$ PCAG B-catenin-mGFP $\mathrm{PA}$ pgk neo' $\mathrm{PA}$

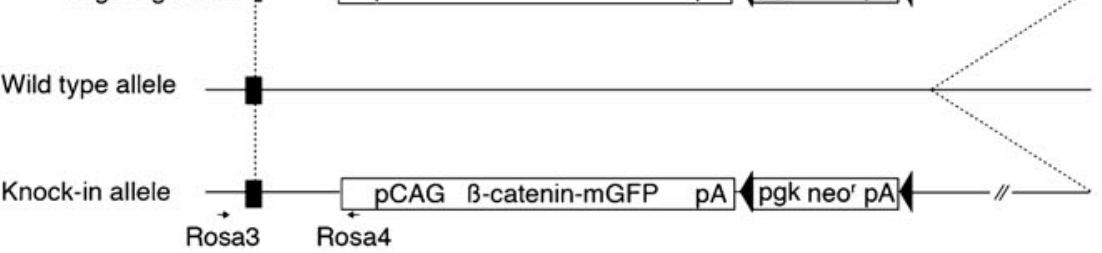

ESC colony
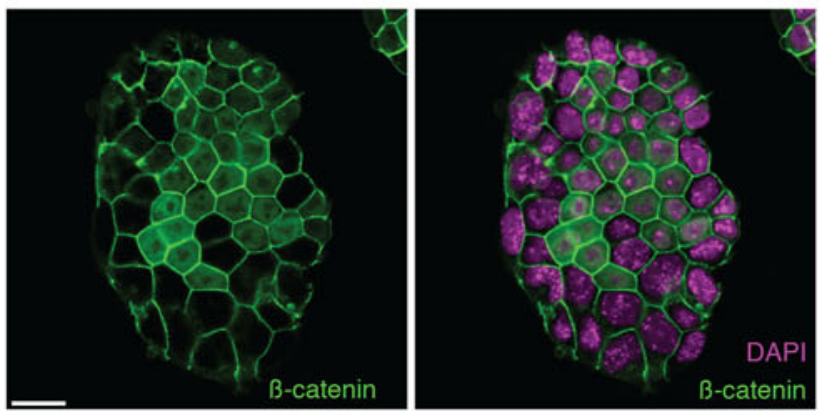

(d)

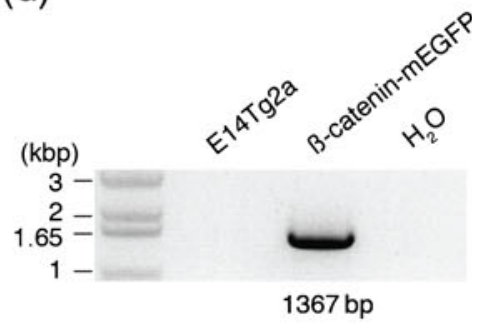

(e)

జ
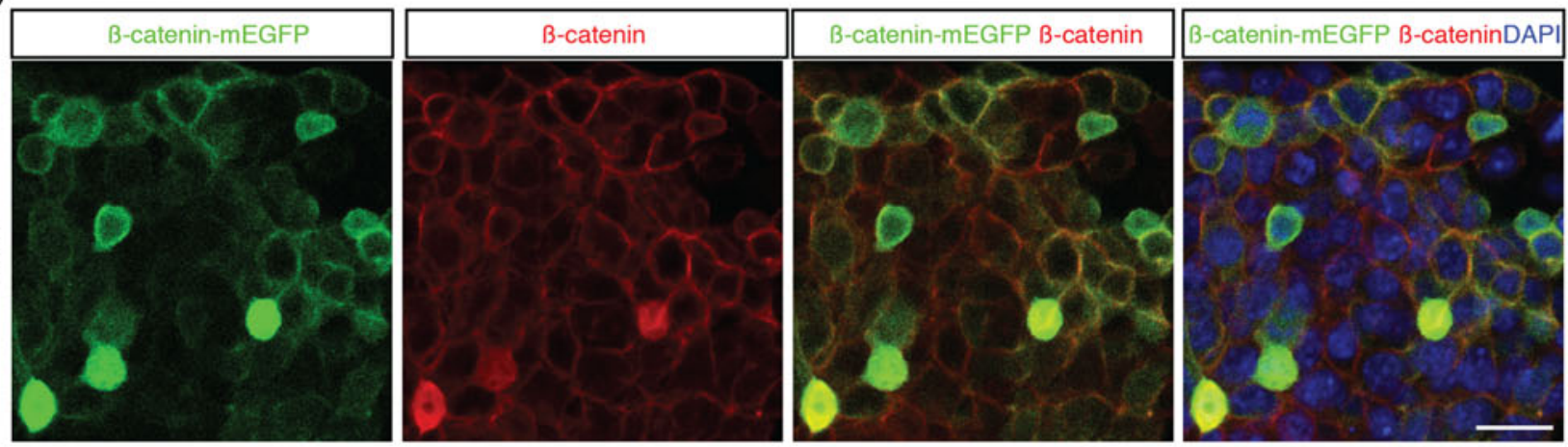

(f)

ESC colony

+1.5 hours

+3 hours

+4.5 hours

+6 hours

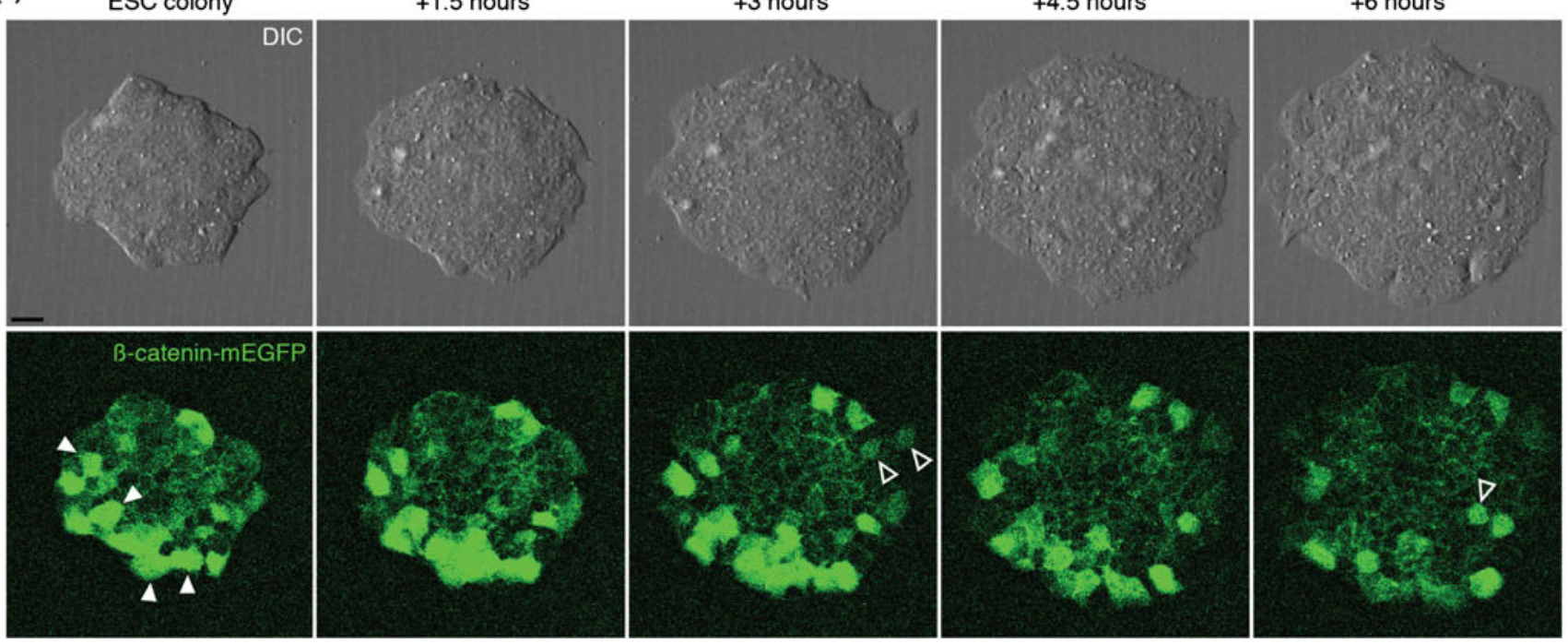


Figure 3. Wnt downstream mediator; $\beta$-catenin was heterogeneously expressed in individual ESCs. (a) Diagram of Wnt/ $\beta$-catenin signaling. (b) Immunohistochemistry was performed on ESC colonies with DAPI using antibodies recognizing $\beta$-catenin. (c) Diagram of Rosa 26 locus knock-in by $\beta$-catenin-mEGFP targeting vector. Black box, exon 1, $p A$ poly adenylation signal, $p g k$ promoter $\mathrm{PGK}, n e o^{r}$ neomycin resistant gene, DT-A A subunit of diphtheria toxin gene under control of PGK promoter, black triangles Cre-mediated site specific sequence for recombination. (d) PCR detection of $\beta$-catenin-mEGFP knocked-in allele. Left lane is DNA ladder marker. E14Tg2a is a parental line. (e) Immunostaining of $\beta$-catenin-mEGFP knocked-in ESC using GFP and $\beta$ catenin antibodies with DAPI. ( $f$ ) Montage of images taken from supplemental video 2 , showing differential interference contrast (DIC) and $\beta$-catenin-mEGFP expression over $6 \mathrm{~h}$. Closed and open triangles indicate $\beta$-catenin-mEGFP signals Off and ON afterward, respectively. Scale bars $25 \mu \mathrm{m}(b, e, f)$.

linearized Rosa26 $\beta$-catenin-mEGFP targeting vector by a restriction enzyme and purified it by phenol-chloroform extraction to eliminate enzyme proteins. Using electroporation grade of linearized vector $(7.5 \mu \mathrm{g})$, we introduced it into $1.0 \times 10^{6}$ E14Tg2a line via A24 program of Amaxa Nucleofector (Lonza, Basel, Switzerland) based on the manufacturer's instruction (day 0). Next at day 2, we add $200 \mu \mathrm{g} / \mathrm{ml} \mathrm{G418} \mathrm{sulfate}$
(10131-035, Gibco) to select pooled homologous recombinant ESCs. Finally, at day 10, we extracted genome of pooled-drugresistant ESCs and performed genotyping of $\beta$-catenin-mEGFP knock-in allele by primers (rosa3, 5'-CCACTGACCGCA CGGGGATTC-3'; rosa4, 5'-TCAATGGGCGGGGG TCGTT-3'). We used pooled knock-in ESCs for Figs. 3 and 4.

Time-laps imaging and analysis. Live-imaging was performed using an incubator-combined confocal optic system (Olympus, Tokyo, Japan) as previously described (Eiraku et al. 2011) using a thin plastic-bottom dish ( $\mu$-Dish, $35 \mathrm{~mm}$, low; ibidi, 80136), supplying penicillin/ streptomycin and then filmed using a LCV110 equipped with 488-nm excitation lasers. We edited acquired images using MetaMorph software (Molecular Devices, Sunnyvale, CA) and Image $\mathrm{J}$ (free software).

RNA extraction, cDNA synthesis, and RT-qPCR. RNA was extracted using the Quiacube (Qiagen, Hilden, Germany) using the company-provided protocol. As previous report (Suga et al. 2011), $350 \mu$ l buffer RLT were

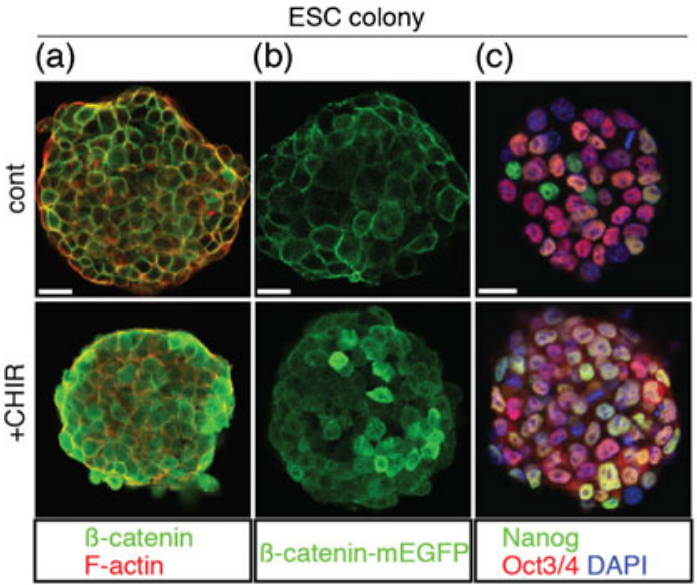

(d)

FACS

B-catenin::mEGFP
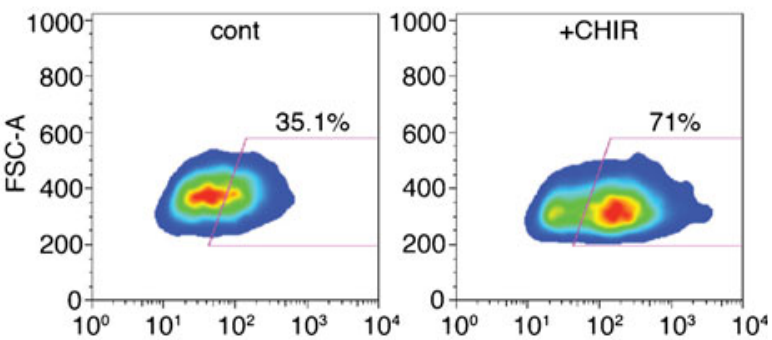

(e)
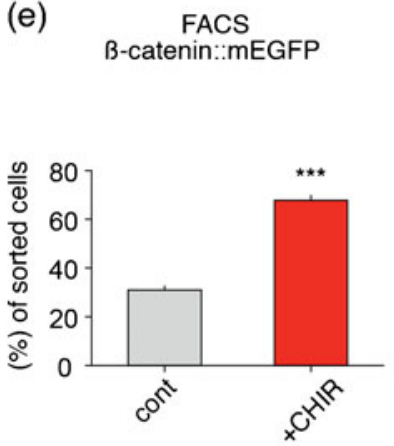

(f)
Wnt antagonist
expression levels in ESC

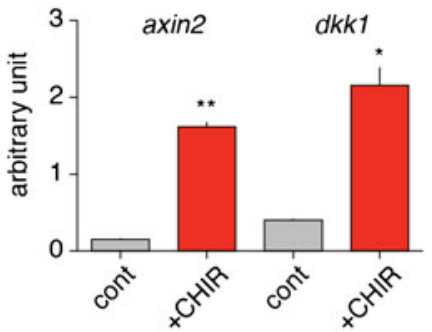

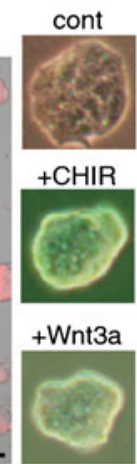

Trans 7Tcf::Cherry
Figure 4. Activation of Wnt signaling increased $\beta$-catenin signals and Wnt target gene expressions. $(a-c)$ Immunohistochemistry was performed on control and CHIR-treated (for $48 \mathrm{~h}$ ) ESC colonies using $\beta$-catenin with phalloidin (a), GFP (b), Nanog and Oct3/4 (c) antibodies. Scale bars $25 \mu \mathrm{m}$. (d) FACS analysis of $\beta$-catenin-mEGFP line. (e) Quantification of $\beta$-catenin-mEGFP positive cells by FACS. (f) Quantification of axin 2 and $d k k 1$ expression via RT-qPCR, following CHIR treatment for 48 h. Error bars indicate standard error of the mean of each experiment. $(g)$ Merged images of transillumination (Trans) and 7Tcf::Cherry signals of ESC colonies by addition of $10 \mu \mathrm{M}$ CHIR for $48 \mathrm{~h}$. Scale bar $100 \mu \mathrm{m}$. Transillumination images of single ESC colony in control, CHIR$(10 \mu \mathrm{M})$ and Wnt3a- $(200 \mathrm{ng} / \mathrm{ml})$ treated condition (for $48 \mathrm{~h})$. 
added to dissociated ESC pellets and spun through QIAshredder (Qiagen) prior to RNA extraction. The cDNA samples for RT-qPCR reactions were generated using the SuperScriptII (18064-014, Invitrogen). The qPCR reactions were performed using a 7500 Fast Real-Time PCR System (Applied Biosystems, Foster City, CA): Standard curves were estimated using a series of dilutions of cDNA purified from mouse ESCs. Primer sets for qPCR are as follows:

\begin{tabular}{lll}
\hline $\begin{array}{l}\text { Gene } \\
\text { GAPDH }\end{array}$ & Forward & Reverse \\
& & GACGGACACATTGG \\
axin2 & TGACTCTCCTTCCAGATCCCA & TGCCCACACTAGGC \\
& & TGACA \\
$d k k 1$ & CCGGGAACTACTGCAAAAAT & CCAAGGTTTCAAT \\
& & GATGCTT \\
\hline
\end{tabular}

Statistics. Statistical analyses were performed with Prism (GraphPad Software, Inc., La Jolla, CA). Data sets were first checked for standard error of the mean. The appropriate test for comparison was performed as follows; $t$ tests (two samples) and Dunnett's test (control and others) were used to generate $P$ values ( $* P<0.05 ; * * P<0.01 ; * * * P<0.001)$.

\section{Results and Discussion}

In this study, we developed a new method for efficient differentiation of $\operatorname{Rax}^{+}$rostral forebrain by activating Wnt signaling through $\beta$-catenin stabilization in mouse ESCs.

To date, the level of Wnt signaling activity in individual stem cells correlates with differences in lineage-specific differentiation propensity (Blauwkamp et al. 2012). Here, we endeavored to extend the idea involving Wnt signaling/ $\beta$-catenin in ESC state and its roles for differentiation, especially in rostral neural lineage.

Rostral forebrain differentiation was accompanied by Wnt signaling and seeding cell number in SFEBq affected Rax ${ }^{+} /$ $\mathrm{Wnt}^{+}$tissue patterning. We first endeavored to analyze Wnt signaling in rostral forebrain differentiation, using SFEBq, which enable us to observe tissue differentiation like that in vivo in three-dimensional (3D) manner (Fig. 1a; see "Materials and Methods" section). We utilized Rax::GFP// 7Tcf::Cherry line to monitor rostral forebrain and Wnt (a) Wnt-priming method
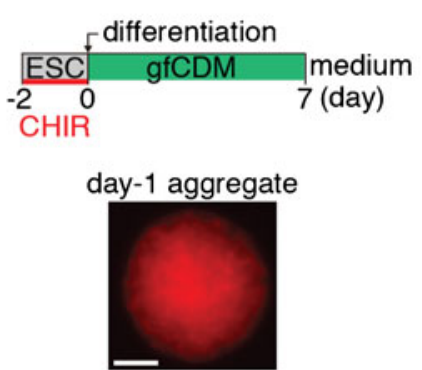

7Tcf::Cherry

(c)

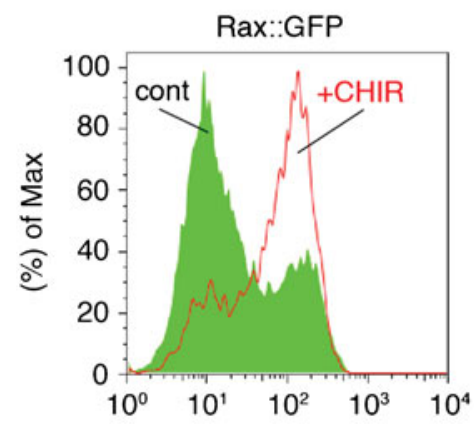

(b)

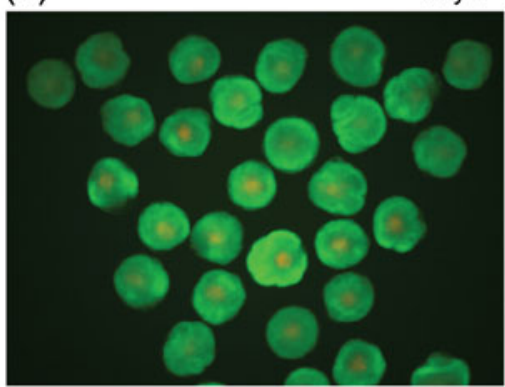

Rax::GFP 7Tcf::Cherry (d)

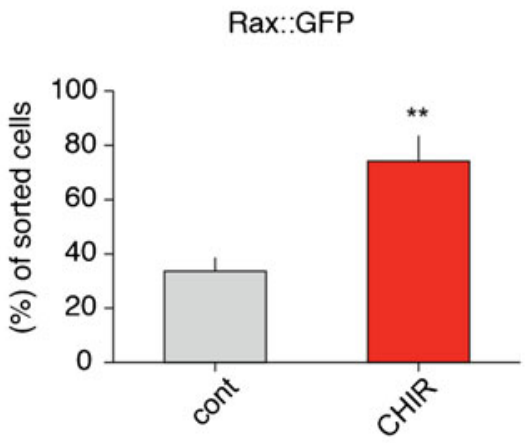

day- 7 tissues

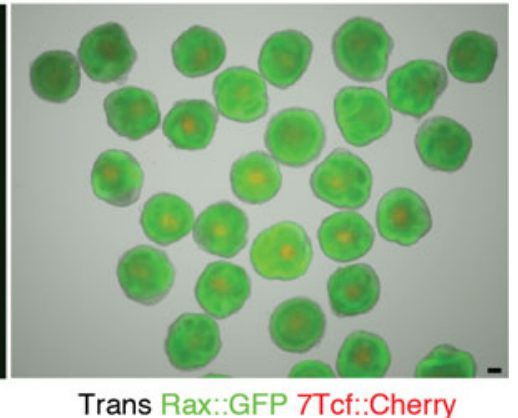

(e) cryosectioned

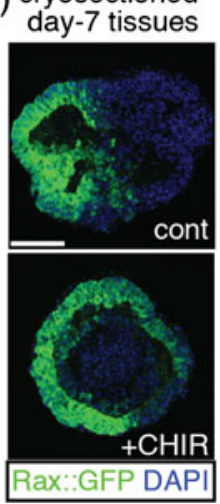

Figure 5. Wnt-priming method promotes rostral forebrain differentiation. (a) Diagram of Wnt-priming method. Day-1 aggregate in this method shows 7Tcf::Cherry signals. (b) Day-7 tissues showing transillumination (Trans), Rax::GFP and 7Tcf::Cherry signals. (c) FACS analysis of CHIR- treated day-7 cells compared with control day-7 cells. Wnt-priming method was not used in control condition. (d) Quantification of Rax::GFP positive cells by FACS. (e) Cryosectioned day-7 tissues, showing Rax::GFP signals with DAPI for counter staining. Scale bars $100 \mu \mathrm{m}(a, b, e)$. 
responding tissues during differentiation and found day-7 tissues showed several Rax::GFP ${ }^{+}$and 7Tcf::Cherry ${ }^{+}$expression patterns among individual tissues (Fig. 1b). The types of expression patterns of tissues were classified into three types as follows: Rax+; most cells expressed Rax:: $\mathrm{GFP}^{+}$, Rax+/Wnt+; Both Rax::GFP ${ }^{+}$and 7Tcf::Cherry ${ }^{+}$patterns within each tissue and Wnt+; Majority of cells are 7Tcf::Cherry ${ }^{+}$or Rax:: $\mathrm{GFP}^{-}$ cells (Fig. 2a). These results imply Wnt signaling is involved in tissue pattern formation and are consistent with previous reports (ten Berge et al. 2008; Petersen and Reddien 2009).

Next, we tested weather seeding number of cells in SFEBq affect the expression patterns of Rax::GFP ${ }^{+}$and 7Tcf::Cherry ${ }^{+}$. Compared with 3000 cells experimental condition, we found that decreasing seeding cell number significantly increased $\mathrm{Wnt}^{+}$ratio but decrease $\mathrm{Rax}^{+}$ratio as seen in 1000 and 500 cells (Fig. 2b). Furthermore, via FACS analysis, Rax::GFP ${ }^{+}$cells were significantly decreased in 1000 and 500 cells condition (Fig. $2 c, d$ ), indicating that population of $\operatorname{Rax}^{+}$ rostral forebrain cells are correlated inversely with Wnt signals and proportionally with seeding cell numbers.

Wnt downstream mediator, $\beta$-catenin expressed heterogeneously in ESCs. Because $\beta$-catenin is an important mediator to activate Wnt target genes in nucleus (Merrill 2012), we then examined the $\beta$-catenin level, prior to SFEBq differentiation, namely ESC state (Fig. 3a). Notably, by detecting endogenous $\beta$-catenin protein, we found cells possessing nuclear $\beta$-catenin signals are partial population, indicating $\beta$-catenin level in ESC state may be highly heterogeneous or low (Fig. $3 b$ and video 1). Heterogeneous activity of endogenous Wnt signaling in individual ESCs was also seen in previous report showing that TCF-GFP reporter was wide range in expression via FACS analysis (Blauwkamp et al. 2012). Next, to observe $\beta$ catenin expression dynamics in living cells, we established knock-in line with $\beta$-catenin::mEGFP under control of CAG promoter in Rosa26 locus in which exogenous genes stably expressed throughout development (Soriano 1999; Abe et al. 2011) (Fig. 3c, $d$; see "Materials and Methods" section). Then, we evaluated the expression and localization of $\beta$ catenin::mEGFP by immunohistochemistry and confirmed $\beta$-catenin::mEGFP signals were comparable to endogenous $\beta$-catenin signals, indicating this knock-in line faithfully represented the $\beta$-catenin signals (Fig. $3 e$; see Fig. $3 b$ for comparison). Subsequently, we observed dynamic $\beta$ catenin::mEGFP signals in live condition and each cell in a colony was heterogeneous in expression dynamics of $\beta$ catenin::mEGFP signals (Fig. $3 f$ and video 2 ). This is consistent with previous report, showing $\beta$-catenin fluctuation in ESCs (Marucci et al. 2014).

Activation of Wht signaling in ESCs promoted rostral forebrain differentiation. To reduce heterogeneous (or low) $\beta$-catenin signals in each cell, we then tested activation of Wnt signaling in ESC state by addition of $10 \mu \mathrm{M}$ CHIR, which inhibits GSK $3 \beta$ to upregulate Wnt signaling through inhibition of $\beta$-catenin degradation (Murray et al. 2004; Clevers 2006; Bain et al. 2007). As compared with control condition, CHIR-treated cells highly expressed $\beta$-catenin in nucleus in each cell (Fig. $4 a, b$ ). In addition, CHIR treatment did not substantially change the pluripotent marker (Niwa 2007; Nichols and Smith 2012), Nanog and Oct3/4 expressions (Fig. $4 c$ ). Notably, we found that strong $\beta$-catenin-expressing population significantly increased in CHIR condition by FACS analysis (Fig. $4 d, e$ ). Next, to confirm the upregulation of Wnt target genes, we performed RT-qPCR analysis and found CHIR treatment strongly increased expression of Wnt antagonist, axin2, and $d k k 1$ as target genes (Jho et al. 2002; Niida et al. 2004) (Fig. 4f). We also observed strong expression of 7Tcf::Cherry in ESCs by addition of CHIR (Fig. $4 g$ ). Furthermore, compact colony morphology was seen in CHIRtreated condition, reminiscent of recombinant Wnt3a-treated condition (Fig. 4g).

These results indicate that activation of Wnt signal directly upregulates $\beta$-catenin in nucleus expression and Wnt antagonists, which then have a potential role for inhibiting Wnt signaling (Kawano and Kypta 2003).

Finally, we tested the efficacy of rostral forebrain differentiation in CHIR-treated condition (hereafter called, Wntpriming method) to stabilize $\beta$-catenin and $\mathrm{Wnt}^{+}$populations during ESC maintenance (Fig. 5a). Surprisingly, we found SFEBq day-7 tissues has clear and strong induction of Rax:: $\mathrm{GFP}^{+}$rostral forebrain differentiation (Fig. $5 b$; see Fig. $1 b$ for comparison). In addition, 7Tcf::Cherry signals at day 1 reduced at day 7 (Fig. 5a, b). FACS analysis showed also CHIR-treated ESCs preferentially differentiated into $\operatorname{Rax}^{+}$cells, compared with control condition (Fig. $5 c, d$ ). By immunostaining following cryosection of tissues, we confirmed that Wnt-priming method promoted Rax::GFP signals of tissue with clear epithelial structure (Fig. 5e).

Although, Wnt inhibition in ESC differentiation promote rostral neural fate (Haegele et al. 2003; Nasu et al. 2012), these results raised a possibility that Wnt antagonists in Wnt-priming method minimized Wnt signaling during rostral forebrain tissue development in vitro. However, future work requires how Wnt antagonists act during in vitro rostral forebrain differentiation in this culture system.

\section{Conclusions}

Research of the relationship between Wnt/ $\beta$-catenin and rostral forebrain lineage using our results will provide useful insights into mechanisms of $\mathrm{Wnt} / \beta$-catenin signaling in ESC culture system for the future improvement of regenerative medicine. 
Acknowledgments We are grateful to M. Eiraku, H. Inomata and M. Ohgushi for invaluable comments and to members of the laboratory for discussion. We also thank $\mathrm{H}$. Kiyonari for critical information about ESC culture, T. Abe for technical advises of Rosa26 knock-in strategy, and M. Kawada for technical advices of SFEBq and vector construction; L. Luo for Rosa26 mTmG. This work was supported by grants-in-aid from Ministry of Education, Culture, Sports, Science, and Technology in Japan (MEXT) (to Y.S.), and the Network Program for Realization of Regenerative Medicine from the Japan Science and Technology Agency (JST) (to Y.S.).

Author contributions N.T. designed the research, N.T. and E.S. performed the experiments, N.T. analyzed the data, N.T. prepared the figures and wrote the paper, and Y.S. supervised the project.

\section{Compliance with ethical standards}

Conflict of interest The authors declare that they have no competing interests.

Open Access This article is distributed under the terms of the Creative Commons Attribution 4.0 International License (http:// creativecommons.org/licenses/by/4.0/), which permits unrestricted use, distribution, and reproduction in any medium, provided you give appropriate credit to the original author(s) and the source, provide a link to the Creative Commons license, and indicate if changes were made.

\section{References}

Abe T, Kiyonari H, Shioi G, Inoue KI, Nakao K, Aizawa S, Fujimori T (2011) Establishment of conditional reporter mouse lines at ROSA26 locus for live cell imaging. Genesis 49:579-590

Abouzeid H, Youssef MA, Bayoumi N, ElShakankiri N, Marzouk I, Hauser P, Schorderet DF (2012) RAX and anophthalmia in humans: evidence of brain anomalies. Mol Vis 18:1449-1456

Andrabi M, Kuraku S, Takata N, Sasai Y, Love NR (2015) Comparative, transcriptome analysis of self-organizing optic tissues. Sci Data 2: 150030

Andreazzoli M, Gestri G, Cremisi F, Casarosa S, Dawid IB, Barsacchi G (2003) Xrx1 controls proliferation and neurogenesis in Xenopus anterior neural plate. Development 130:5143-5154

Atlasi Y, Noori R, Gaspar C, Franken P, Sacchetti A, Rafati H, Mahmoudi T, Decraene C, Calin GA, Merrill BJ et al (2013) Wnt signaling regulates the lineage differentiation potential of mouse embryonic stem cells through Tcf3 down-regulation. Plos Genet 9

Bain J, Plater L, Elliott M, Shpiro N, Hastie CJ, Mclauchlan H, Klevernic I, Arthur JSC, Alessi DR, Cohen P (2007) The selectivity of protein kinase inhibitors: a further update. Biochem J 408:297-315

Blauwkamp TA, Nigam S, Ardehali R, Weissman IL, Nusse R (2012) Endogenous Wnt signalling in human embryonic stem cells generates an equilibrium of distinct lineage-specified progenitors. Nat Commun 3:1070

Bouhon IA, Kato H, Chandran S, Allen ND (2005) Neural differentiation of mouse embryonic stem cells in chemically defined medium. Brain Res Bull 68:62-75

Clevers H (2006) Wnt/beta-catenin signaling in development and disease. Cell 127:469-480

Eiraku M, Takata N, Ishibashi H, Kawada M, Sakakura E, Okuda S, Sekiguchi K, Adachi T, Sasai Y (2011) Self-organizing optic-cup morphogenesis in three-dimensional culture. Nature 472:51-U73
Furukawa T, Kozak CA, Cepko CL (1997) rax, a novel paired-type homeobox gene, shows expression in the anterior neural fold and developing retina. Proc Natl Acad Sci U S A 94:3088-3093

Haegele L, Ingold B, Naumann H, Tabatabai G, Ledermann B, Brandner S (2003) Wnt signalling inhibits neural differentiation of embryonic stem cells by controlling bone morphogenetic protein expression. Mol Cell Neurosci 24:696-708

Hooper M, Hardy K, Handyside A, Hunter S, Monk M (1987) HPRTdeficient (Lesch-Nyhan) mouse embryos derived from germline colonization by cultured cells. Nature 326:292-295

Jho EH, Zhang T, Domon C, Joo CK, Freund JN, Costantini F (2002) Wnt/beta-catenin/Tcf signaling induces the transcription of Axin2, a negative regulator of the signaling pathway. Mol Cell Biol 22:11721183

Kamiya D, Banno S, Sasai N, Ohgushi M, Inomata H, Watanabe K, Kawada M, Yakura R, Kiyonari H, Nakao K et al (2011) Intrinsic transition of embryonic stem-cell differentiation into neural progenitors. Nature 470:503-U592

Kawano Y, Kypta R (2003) Secreted antagonists of the Wnt signalling pathway. J Cell Sci 116:2627-2634

Kielman MF, Rindapaa M, Gaspar C, van Poppel N, Breukel C, van Leeuwen S, Taketo MM, Roberts S, Smits R, Fodde R (2002) Apc modulates embryonic stem-cell differentiation by controlling the dosage of beta-catenin signaling. Nat Genet 32:594-605

Li WL, Ding S (2010) Small molecules that modulate embryonic stem cell fate and somatic cell reprogramming. Trends Pharmacol Sci 31: 36-45

Markakis EA (2002) Development of the neuroendocrine hypothalamus. Front Neuroendocrinol 23:257-291

Marks H, Kalkan T, Menafra R, Denissov S, Jones K, Hofemeister H, Nichols J, Kranz A, Stewart AF, Smith A et al (2012) The transcriptional and epigenomic foundations of ground state pluripotency. Cell 149:590-604

Marucci L, Pedone E, Di Vicino U, Sanuy-Escribano B, Isalan M, Cosma MP (2014) Beta-catenin fluctuates in mouse ESCs and is essential for nanog-mediated reprogramming of somatic cells to pluripotency. Cell Rep 8:1686-1696

Mathers PH, Grinberg A, Mahon KA, Jamrich M (1997) The Rx homeobox gene is essential for vertebrate eye development. Nature 387 : 603-607

Mathers PH, Jamrich M (2000) Regulation of eye formation by the Rx and pax6 homeobox genes. Cell Mol Life Sci 57:186-194

Merrill BJ (2012) Wnt pathway regulation of embryonic stem cell selfrenewal. Cold Spring Harb Perspect Biol 4(9):a007971

Murray JT, Campbell DG, Morrice N, Auld GC, Shpiro N, Marquez R, Peggie M, Bain J, Bloomberg GB, Grahammer F et al (2004) Exploitation of KESTREL to identify NDRG family members as physiological substrates for SGK1 and GSK3. Biochem J 384:477-488

Muzumdar MD, Tasic B, Miyamichi K, Li L, Luo LQ (2007) A global double-fluorescent cre reporter mouse. Genesis 45:593-605

Nakagawa S (2004) The role of Wnt signaling in eye organogenesis. Seikagaku 76:1573-1576

Nasu M, Takata N, Danjo T, Sakaguchi H, Kadoshima T, Futaki S, Sekiguchi K, Eiraku M, Sasai Y (2012) Robust formation and maintenance of continuous stratified cortical neuroepithelium by laminincontaining matrix in mouse ES cell culture. PLoS One 7, e53024

Nichols J, Smith A (2012) Pluripotency in the embryo and in culture. Cold Spring Harb Perspect Biol 4:a008128

Niida A, Hiroko T, Kasai M, Furukawa Y, Nakamura Y, Suzuki Y, Sugano S, Akiyama T (2004) DKK1, a negative regulator of Wnt signaling, is a target of the beta-catenin/TCF pathway. Oncogene 23: $8520-8526$

Niwa H (2007) How is pluripotency determined and maintained? Development 134:635-646

Nusse R (2008) Wnt signaling and stem cell control. Cell Res 18:523-527 
Nusse R, Fuerer C, Ching W, Harnish K, Logan C, Zeng A, ten Berge D, Kalani Y (2008) Wnt signaling and stem cell control. Cold Spring Harb Symp Quant Biol 73:59-66

Ohgushi M, Minaguchi M, Sasai Y (2015) Rho-signaling-directed YAP/ TAZ activity underlies the long-term survival and expansion of human embryonic stem cells. Cell Stem Cell 17(4):448-461

Ohuchi H, Tomonari S, Itoh H, Mikawa T, Noji S (1999) Identification of chick rax/rx genes with overlapping patterns of expression during early eye and brain development. Mech Dev 85:193-195

Petersen CP, Reddien PW (2009) Wnt signaling and the polarity of the primary body axis. Cell 139:1056-1068

Plusa B, Hadjantonakis AK (2014) Embryonic stem cell identity grounded in the embryo. Nat Cell Biol 16:502-504

Price FD, Yin H, Jones A, van Ijcken W, Grosveld F, Rudnicki MA (2013) Canonical Wnt signaling induces a primitive endoderm metastable state in mouse embryonic stem cells. Stem Cells 31: $752-764$

Ruiz i Altaba A (1998) Neural patterning. Deconstructing the organizer. Nature 391:748-749

Sinn R, Wittbrodt J (2013) An eye on eye development. Mech Dev 130: 347-358

Soriano P (1999) Generalized lacZ expression with the ROSA26 Cre reporter strain. Nat Genet 21:70-71

Suga H, Kadoshima T, Minaguchi M, Ohgushi M, Soen M, Nakano T, Takata N, Wataya T, Muguruma K, Miyoshi H et al (2011) Selfformation of functional adenohypophysis in three-dimensional culture. Nature 480:57-U215 ten Berge D, Koole W, Fuerer C, Fish M, Eroglu E, Nusse R (2008) Wnt signaling mediates self-organization and axis formation in embryoid bodies. Cell Stem Cell 3:508-518

ten Berge D, Kurek D, Blauwkamp T, Koole W, Maas A, Eroglu E, Siu RK, Nusse R (2011) Embryonic stem cells require Wnt proteins to prevent differentiation to epiblast stem cells. Nat Cell Biol 13:1070 1075

Voronina VA, Kozhemyakina EA, O'Kernick CM, Kahn ND, Wenger SL, Linberg JV, Schneider AS, Mathers PH (2004) Mutations in the human RAX homeobox gene in a patient with anophthalmia and sclerocornea. Hum Mol Genet 13:315-322

Wataya T, Ando S, Muguruma K, Ikeda H, Watanabe K, Eiraku M, Kawada M, Takahashi J, Hashimoto N, Sasai Y (2008) Minimization of exogenous signals in ES cell culture induces rostral hypothalamic differentiation. Proc Natl Acad Sci U S A 105:1179611801

Wiles MV, Johansson BM (1999) Embryonic stem cell development in a chemically defined medium. Exp Cell Res 247:241-248

Wilson SW, Houart C (2004) Early steps in the development of the forebrain. Dev Cell 6:167-181

Ying QL, Wray J, Nichols J, Batlle-Morera L, Doble B, Woodgett J, Cohen P, Smith A (2008) The ground state of embryonic stem cell self-renewal. Nature 453:519-523

Zhang L, Mathers PH, Jamrich M (2000) Function of Rx, but not Pax6, is essential for the formation of retinal progenitor cells in mice. Genesis 28:135-142 